\title{
Relationship between student guidance and academic achievement
}

\section{Lukkarinen, Anna ${ }^{a}$ and Koivukangas, Paula ${ }^{b}$}

${ }^{a}$ Department of Information and Service Management, Aalto University School of Business, Finland, ${ }^{\mathrm{b}}$ Learning Services, Aalto University School of Business, Finland.

\begin{abstract}
We assess how different types of guidance offered to first-year students are related to the students' subsequent academic performance. Using data from a student survey conducted at a Finnish business university, as well as the university's student database, we build regression models to predict student performance. We find that guidance on choosing a major subject and guidance on study methods are significant predictors of subsequent performance. More tactical types of guidance are not statistically significant, and can be rather considered as enablers. The quantitative findings are supported by verbal feedback collected from students. We conclude that guidance offered to students at the start of their university careers can bear fruit still several years afterwards. The findings have implications for university educators and staff responsible for the orientation of first-year students. Educators and staff can seek to enhance academic achievement by ensuring that students are equipped with sufficient methods and skills necessary for their university studies and by providing students with extensive information on possible study paths beyond the first year.
\end{abstract}

Keywords: Academic achievement; first-year students; student guidance; student onboarding; student performance. 


\section{Introduction}

Starting university studies entails a major change to many individuals. The typical plethora of degree structures, course offerings, information systems, and study methods can be a lot to absorb for new students. In a relatively short period of time, students need to adapt to a new environment, begin mastering the practical skills necessary for university studies, and start learning course content. As the learning skills used in high school are often not sufficient at university level, students also need to find new ways of learning (Cook \& Leckey, 1999). Furthermore, several additional tasks, such as making a personal study plan, can seem challenging.

The first year at university plays a crucial role in shaping students' commitment and study progress in subsequent years (Tinto, 2006). According to Haarala-Muhonen (2011), good learning skills and first-year students' ability to systematically plan their studies are key factors affecting the progress and success of university studies.

Universities typically provide first-year students with guidance and counselling to assist them in adapting to, and navigating through, their university studies. The fundamental aim of guidance is to ensure that students are able to complete their degree successfully and within the normative time frame. Indeed, undergraduate guidance and counselling have been shown to be related to successful degree completion (Rickinson, 1998) and grades (Devi et al., 2013). Tinto (2003) highlights the benefit of investing in study guidance and support especially during the first study year.

In this paper, we assess different types of guidance given to first-year students in order to understand which types of guidance are related to subsequent academic performance. The findings are relevant for university educators and staff who plan and implement guidance and onboarding activities to students.

\section{Method}

\subsection{Empirical context}

We study student guidance and academic achievement in the context of a Finnish business university. During the first year, students complete a standard package of studies worth 60 European Credit Transfer and Accumulation System (ECTS) credits. It provides students with the core knowledge and skills necessary in business studies and creates a basis for completing the rest of their bachelor's and master's degrees.

This first-year package includes an onboarding course taught by a professional study tutor. The tutor represents a single point of contact to whom first-year students can turn with any questions, be they methodical, practical, or related to career or course planning. The 
onboarding course begins with an intensive orientation week, continues with several meetings spread out through the year, and intensifies again in the spring when reflecting on academic aims and career goals becomes topical.

At the end of the first year, students choose their specialization area (or major) for the two following years. Selection of students to the more competitive specialization areas is based on the credits and grades earned during the first year.

\subsection{Data}

We use two data sources from within the university. The first is an online survey that was administered to all first-year students in spring 2015, towards the end of the academic year. The survey data includes full responses from 270 students. The survey provides information about students' perceptions of different dimensions of their first year of studies as well as expectations for the future. Responding to the questionnaire is part of the onboarding course, and students dedicate time and effort to responding. In addition to Likert scale questions, the survey includes several free text questions, to which each student responded with, on average, a total of 152 words.

The second data source is the internal student information database of the university. It hosts data on completed courses and grades, as well as background information on all students.

We use multiple regression analysis to analyze the quantitative data. In addition, we qualitatively assess students' verbal survey responses.

\subsection{Variables}

The explained variable measures students' academic achievement:

Average grade. The weighted grade point average of all courses completed by the student during the five semesters that have passed since the beginning of the studies in fall 2015.

The explanatory variables reflect students' views on the sufficiency of different types of guidance they received during their first year of studies. Each variable is measured with a five-point Likert scale ranging from "fully disagree" (1) to "fully agree" (5):

Guidance on planning. Students' assessment of whether they received sufficient guidance on planning their first year of studies.

Guidance on choosing. Students' assessment of whether they received sufficient guidance on choosing a major for their bachelor's degree. 
Guidance on practicalities. Students' assessment of whether they received sufficient guidance on the practical matters of studying (e.g., signing up to courses and exams).

Guidance on methods. Students' assessment of whether they received sufficient information or guidance on study methods and skills.

In addition, the following control variables are included in the models:

Study hours. Estimated average number of hours the student used for studying per week.

First attempt. Dummy variable that equals 1 if the student was admitted to the university the first time she/he took the entrance exam, and 0 otherwise.

Gender. Dummy variable that equals 1 if the student is female, and 0 if the student is male (other options for gender are currently not possible in the university's information system).

Age. The student's age in years at the beginning of year 2018.

\section{Results}

\subsection{Descriptive statistics}

Descriptive statistics for all variables are presented in Table 1.

Table 1: Descriptive statistics

\begin{tabular}{lrrrrrr}
\hline Variables & N & Min & Max & Mean & $\begin{array}{r}\text { Median } \\
\text { Standard } \\
\text { deviation }\end{array}$ \\
\hline Explained variable & & & & & & \\
\hline Average grade & 270 & 2.55 & 4.94 & 3.71 & 3.67 & 0.54 \\
Explanatory variables & & & & & & \\
\hline Guidance on planning & 270 & 1.00 & 5.00 & 4.03 & 4.00 & 1.04 \\
Guidance on choosing & 270 & 1.00 & 5.00 & 3.98 & 4.00 & 0.97 \\
Guidance on practicalities & 270 & 1.00 & 5.00 & 4.26 & 4.00 & 0.92 \\
Guidance on methods & 270 & 1.00 & 5.00 & 3.88 & 4.00 & 0.97 \\
Control variables & & & & & & \\
\hline Study hours & 255 & 4.00 & 80.00 & 30.10 & 30.00 & 14.16 \\
First attempt & 270 & 0.00 & 1.00 & 0.67 & 1.00 & 0.47 \\
Gender & 270 & 0.00 & 1.00 & 0.40 & 0.00 & 0.49 \\
Age & 270 & 20.00 & 55.00 & 23.33 & 22.50 & 3.56 \\
\hline
\end{tabular}

Overall, students perceived that they had received sufficient guidance across the different types of guidance. Guidance on practical matters was perceived to be the most sufficient, while guidance on study methods and skills exhibited the most room for improvement. 
Correlations between all variables are presented in Table 2. Sufficiency of guidance on choosing a major and sufficiency of guidance on study methods and skills are positively related to the average grade, whereas guidance on planning the first year and guidance on practicalities are not related to the average grade in a statistically significant manner.

Table 2: Correlations

\begin{tabular}{llccccccr}
\hline Variables & $\mathbf{1}$ & $\mathbf{2}$ & $\mathbf{3}$ & $\mathbf{4}$ & $\mathbf{5}$ & $\mathbf{6}$ & $\mathbf{7}$ & $\mathbf{8}$ \\
\hline 1 Average grade & & & & & & & & \\
2 Guidance on planning & 0.11 & & & & & & & \\
3 Guidance on choosing & $0.18^{*}$ & $0.60^{*}$ & & & & & & \\
4 Guidance on practicalities & 0.10 & $0.67^{*}$ & $0.51^{*}$ & & & & & \\
5 Guidance on methods & $0.16^{*}$ & $0.57^{*}$ & $0.55^{*}$ & $0.56^{*}$ & & & & \\
6 Study hours & $0.33^{*}$ & -0.02 & -0.01 & 0.00 & -0.05 & & & \\
7 First attempt & $0.29^{*}$ & 0.01 & 0.03 & -0.06 & 0.00 & 0.02 & & \\
8 Gender & $-0.15^{*}$ & $-0.15^{*}$ & $-0.16^{*}$ & $-0.19^{*}$ & $-0.13^{*}$ & 0.05 & 0.01 & \\
9 Age & -0.07 & 0.06 & 0.08 & 0.07 & 0.09 & -0.06 & $-0.20^{*}$ & -0.08 \\
\hline
\end{tabular}

Significance: $* \mathrm{p}<0.05$. Pearson correlation coefficient presented for correlations between scale (or Likert scale) variables. Point-biserial correlation presented for correlations between scale (or Likert scale) and indicator variables. Phi-coefficient presented for correlations between indicator variables. As a robustness check, we calculated also Spearman correlation coefficients, with no relevant changes in statistical significance.

\subsection{Predictors of performance}

Regression models to predict student performance, as measured by the average grade, are presented in Table 3. Separate models are presented for each type of guidance.

Guidance on choosing a major and guidance on study methods and skills are statistically significant predictors of the average grade. Guidance on planning the first year of studies and guidance on practicalities are not statistically significant. Results for the control variables are consistent across models. The hours studied per week are positively related to performance. Students who were accepted at their first attempt at the entrance exam perform better than others, and men earn higher average grades than women. Age is not related to performance in a statistically significant manner. 
Table 3: Regression models predicting the average grade

\begin{tabular}{lcccc}
\hline Variables & Model 1 & Model 2 & Model 3 & Model 4 \\
\hline Constant & $3.013^{* *}$ & $2.878^{* *}$ & $2.996^{* *}$ & $2.910^{* *}$ \\
Guidance on planning & $(0.255)$ & $(0.255)$ & $(0.266)$ & $(0.249)$ \\
& 0.047 & & & \\
Guidance on choosing & $(0.029)$ & & & \\
Guidance on practicalities & & $0.086^{* *}$ & & \\
& & $(0.032)$ & & \\
Guidance on methods & & & 0.048 & $0.083^{* *}$ \\
& & & & $(0.031)$ \\
Study hours & $0.013^{* *}$ & $0.013^{* *}$ & $0.013^{* *}$ & $0.013^{* *}$ \\
& $(0.002)$ & $(0.002)$ & $(0.002)$ & $(0.002)$ \\
First attempt & $0.327^{* *}$ & $0.321^{* *}$ & $0.331^{* *}$ & $0.324^{* *}$ \\
& $(0.066)$ & $(0.065)$ & $(0.066)$ & $(0.065)$ \\
Gender & $-0.162^{*}$ & $-0.155^{*}$ & $-0.158^{*}$ & $-0.154^{*}$ \\
& $(0.063)$ & $(0.062)$ & $(0.064)$ & $(0.062)$ \\
Age & -0.002 & -0.002 & -0.002 & -0.003 \\
& $(0.009)$ & $(0.008)$ & $(0.009)$ & $(0.008)$ \\
\hline $\mathrm{R}^{2}$ & 0.221 & 0.236 & 0.220 & 0.236 \\
Adjusted $\mathrm{R}^{2}$ & 0.206 & 0.220 & 0.204 & 0.221 \\
\hline
\end{tabular}

Significance: $* * p<0.01 ; * p<0.05$. Standard error in parentheses. The models do not suffer from multicollinearity (as indicated by variance inflation factors) or from error term non-normality (as indicated by the Bera-Jarque test). The relationship between the dependent and independent variables appears linear (as indicated by plots of studentized residuals against predicted values).

\subsection{Insights from students}

In addition to the Likert scale questions, the survey asked students to verbally share their views on the topics on which they would have hoped to receive more information or guidance. To gain further insight into the relevance and improvement areas of guidance, we analyzed these verbal answers.

Although many students expressed their full satisfaction with the current guidance provided, certain areas arose as clearly the most relevant ones in terms of importance and improvement potential. They are summarized in Figure 1.

Many students hoped for more concrete and early advice on selecting their major and minor subjects, and for planning their study paths beyond the first year. Many respondents called for information about ways to customize one's studies by, for instance, selecting less typical courses or course providers, or by using alternative ways of completing courses. In 
addition, several students felt that they would benefit from further guidance about study techniques and manners, as well as the skills necessary in a university environment. Although the quantitative responses indicated that guidance on practical matters had been sufficient, several respondents raised the need for further guidance on using electronic course systems. Finally, some respondents suggested that the university facilitate information sessions with more senior students representing different majors.

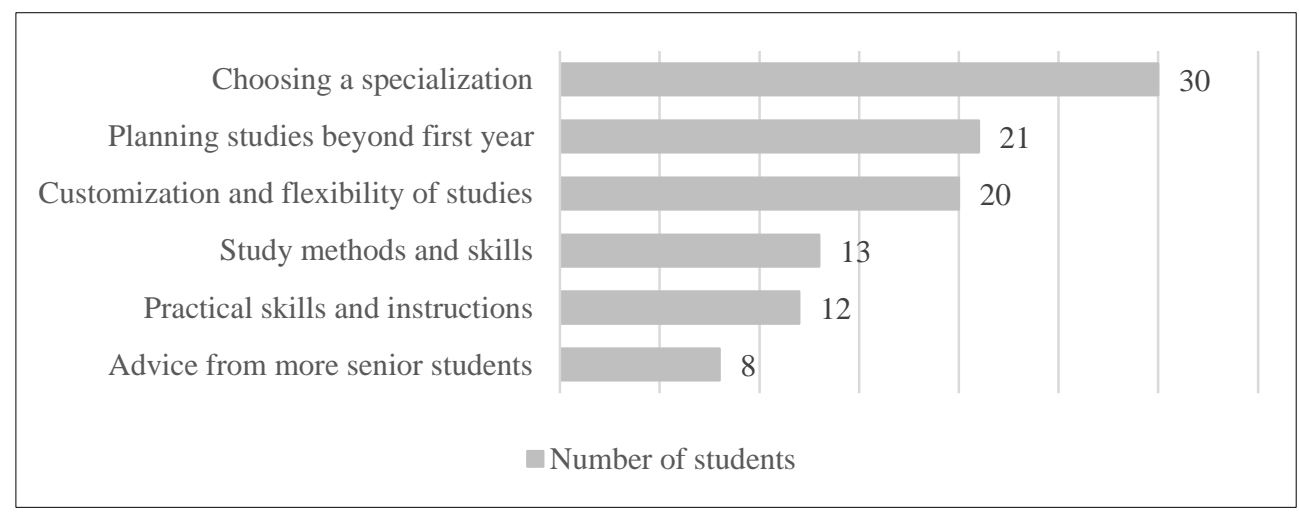

Figure 1: Areas of specific importance and improvement in student guidance mentioned in the verbal answers.

It is also interesting to note that many respondents acknowledged that sufficient guidance would have been available, but that they remained uninformed of certain topics because they had not participated in the relevant sessions or read the relevant materials. It is thus not only important to consider what guidance is provided to students, but also how it is delivered in an accessible and attractive manner.

\section{Conclusions}

We have shown that the guidance offered to first-year students at a business university is related to students' subsequent academic performance. Quantitative results were supported by qualitative feedback from students. In particular, strategic types of guidance that relate to students' choice of study direction and to appropriate study methods are significant predictors of academic achievement. More tactical types of guidance related to implementing the first year of studies and handling practical matters were not observed to be related to performance, and can rather be considered as necessary enablers.

The findings have implications for university educators and staff responsible for the orientation of first-year students. Educators and staff can seek to enhance academic achievement by providing students with sufficient guidance on strategic topics in an accessible and attractive manner. This may include, for example, facilitating students' encounters with more senior students or academic staff representing different specialization 
areas. The findings emphasize that many first-year students need extensive guidance in order to successfully adapt to the academic environment. Appropriate guidance can assist students in selecting a study path most suitable for their individual preferences and in using efficient and effective learning techniques, thereby supporting students in reaching their fundamental academic goals.

\section{References}

Cook, A. \& Leckey, J. (1999). Do expectations meet reality? A survey of changes in firstyear student opinion. Journal of Further \& Higher Education, 23(2), 157-171.

Devi, R., Devaki, P.R., Madhavan, M., \& Saikumar, P. (2013). The effect of counselling on the academic performance of college students. Journal of Clinical and Diagnostic Research, 7(6), 1086-1088.

Haarala-Muhonen, A. (2011). First-year law students' challenges in studying (Doctoral dissertation). Retrieved from HELDA - Digital Repository of the University of Helsinki.

Rickinson, B. (1998). The relationship between undergraduate student counselling and successful degree completion. Studies in Higher Education, 23(1), 95-102.

Tinto, V. (2003). Promoting student retention through classroom practice. Presented at Enhancing Student Retention: Using International Policy and Practice, Amsterdam, the Netherlands.

Tinto, V. (2006). Research and practice of student retention: What next? Journal of College Student Retention, 8, 1-19. 